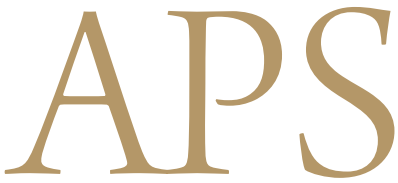

Archives of Plastic Surgery

\title{
Technical Aspects and Difficulties in the Management of Head and Neck Cutaneous Malignancies in Xeroderma Pigmentosum
}

\author{
Serhat Sibar ${ }^{1}$, Kemal Findikcioglu ${ }^{1}$, Ayhan Isik Erdal ${ }^{1}$, Ismail Barut ${ }^{1}$, Selahattin Ozmen ${ }^{2}$ \\ ${ }^{1}$ Department of Plastic, Reconstructive and Aesthetic Surgery, Gazi University Hospital, Ankara; ${ }^{2}$ Department of Plastic, Reconstructive and \\ Aesthetic Surgery, Koc University Hospital, Istanbul, Turkey
}

Background Xeroderma pigmentosum (XP) is an autosomal recessive disorder characterized by xerosis, ultraviolet light sensitivity, and cutaneous dyspigmentation. Due to defects in their DNA repair mechanism, genetic mutations and carcinogenesis inevitably occurs in almost all patients. In these patients, reconstruction of cutaneous malignancies in the head and neck area is associated with some challenges such as likelihood of recurrence and an aggressive clinical course. The aim of this study is to discuss the therapeutic options and challenges commonly seen during the course of treatment.

Methods Between 2005 and 2015, 11 XP patients with head and neck cutaneous malignancies were included in this study. Demographic data and treatment options of the patients were evaluated.

Results The mean age of the patients was 32 years (range, 10-43) (4 males, 7 females). The most common tumor type and location were squamous cell carcinoma (6 patients) and the orbital region (4 patients), respectively. Free tissue transfer was the most commonly performed surgical intervention (4 patients). The average number of surgical procedures was 5.5 (range, 1-25). Six patients were siblings with each other, 5 patients had local recurrences, and one patient was lost to follow-up.

Conclusions Although genetic components of the disease have been elucidated, there is no definitive treatment algorithm. Early surgical intervention and close follow-up are the gold standard modalities due to the tendency toward rapid tumor growth and possible recurrence. Treatment must be individualized for each patient. In addition, the psychological aspect of the disease is an important issue for both patients and families.

Keywords Skin neoplasms / Head and neck neoplasms / Xeroderma pigmentosum / Free tissue flaps

Received: 7 Feb 2016• Revised: 1 Jun 2016• Accepted: 7 Jun 2016

pISSN: 2234-6163 • elSSN: 2234-6171 • http://dx.doi.org/10.5999/aps.2016.43.4.344• Arch Plast Surg 2016;43:344-351
Correspondence: Serhat Sibar Department of Plastic, Reconstructive and Aesthetic Surgery, Gazi University Hospital, 14th floor, Besevler, 06500, Ankara, Turkey

Tel: +90-312-202-6418

Fax: +90-312-212-9908

E-mail: serhatsibar@hotmail.com

No potential conflict of interest relevant to this article was reported.

\section{INTRODUCTION}

Xeroderma pigmentosum (XP) is an autosomal recessive disorder characterized by an endonuclease enzyme defect. Solar sen- sitivity (sunburns with severe bullous lesions, facial freckles), ocular involvement (photophobia, keratitis, atrophy of the eyelid skin), and increased tendency to cutaneous malignancies (squamous cell carcinoma [SCC], basal cell carcinoma [BCC], 
melanoma) are the three main clinical features of the disease. It was first described by Moriz Kaposi in 1870, and the etiology and pathogenesis were elucidated by James Cleaver in 1968 [14]. Solar injury and aging is evident in the regions exposed to the sun, with sharp boundaries between exposed and non-exposed regions. Eight subtypes of the disease have been defined including seven groups ranging between $A$ and $G$ (XP-A, ...-G) and a variant group (XP variant). Each subtype has a distinct clinical presentation and course with wide variation across patients [5-7]. The most common forms are the XP-A, XP-C, and $\mathrm{XP}-\mathrm{D}$ subtypes, which are more commonly associated with cutaneous malignancies. XP-E and XP-F subtypes are relatively rare and characterized by a milder course in which cutaneous malignancies develop at later ages [8]. The onset of the disease is typically in the first or second year of life with acute sunburn; at later stages, skin pigmentation, dryness, freckles, and finally cutaneous malignancies develop. Cutaneous malignancies are mostly SCCs and BCCs developed in association with solar elastosis and less commonly, malignant melanomas. These tumors are more common in the head and neck region, which generally has more sun exposure, when compared to the other parts of the body. This study examined treatment alternatives and challenges in our $11 \mathrm{XP}$ patients with cutaneous malignancies in the head and neck region.

\section{METHODS}

Eleven XP patients admitted to our institution with a localized cutaneous malignancy between 2005 and 2015 were included in this retrospective study. The medical records of the patients were examined for the following parameters: age, gender, age at the onset of the first tumor, tumor type, mean survival, number and type of operations, recurrence, adjuvant treatment, internal organ metastasis, and family history. All patients had been diagnosed in another institution by the demonstration of the deficiency in the DNA repair capacity in cell cultures from skin biopsies when they were exposed to Ultraviolet mediated injury, and the diagnoses had been supported by physical examination findings of dermal solar injury and ocular involvement as well as the presence of cutaneous malignancies.

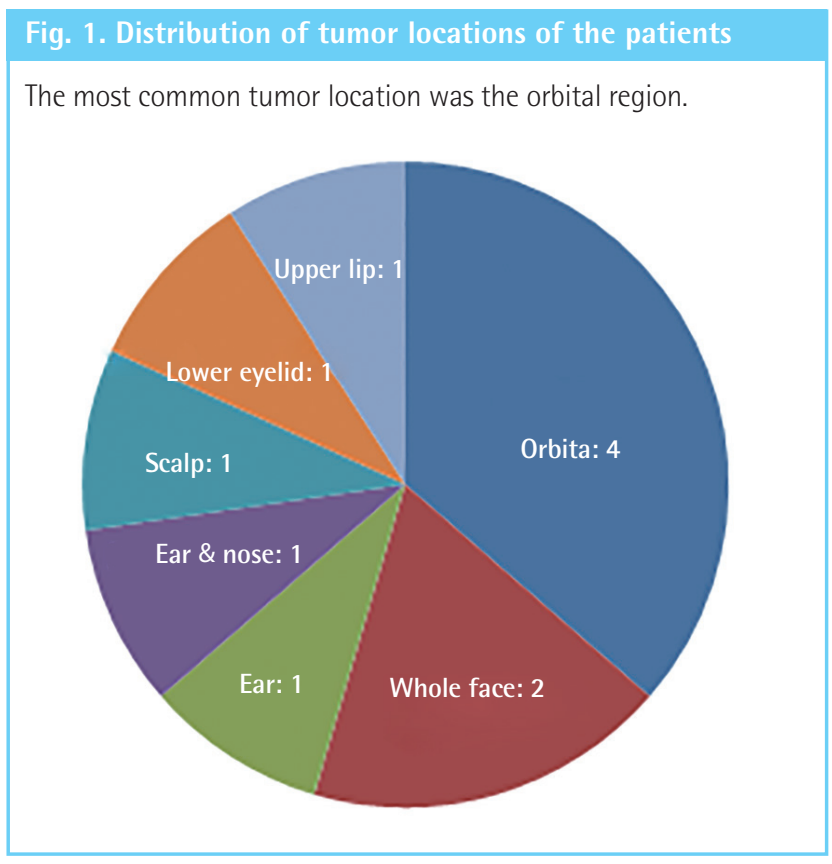

\section{Table 1. Clinical features of patients}

\begin{tabular}{|c|c|c|c|c|c|c|c|c|c|c|}
\hline $\begin{array}{c}\text { Patient } \\
\text { no. }\end{array}$ & $\begin{array}{l}\text { Age } \\
(y r)\end{array}$ & $\begin{array}{c}\text { Age of first } \\
\text { tumor } \\
\text { onset }\end{array}$ & Sex & $\begin{array}{l}\text { Histology/ } \\
\text { Localization }\end{array}$ & Survival & Reconstruction method & $\begin{array}{l}\text { Adjuvant } \\
\text { therapy }\end{array}$ & $\begin{array}{l}\text { Recur- } \\
\text { rence }\end{array}$ & $\begin{array}{l}\text { Metas- } \\
\text { tasis }\end{array}$ & $\begin{array}{r}\text { Family } \\
\text { history }\end{array}$ \\
\hline $1^{\text {a) }}$ & 36 & 20 & Male & SCC/Orbit & - & VRAM & + & + & + & + \\
\hline $2^{\text {a) }}$ & 43 & 33 & Male & SCC/Orbit & + & VRAM & + & + & + & + \\
\hline $3^{\mathrm{a}, \mathrm{b})}$ & 26 & 24 & Female & SCC/Orbit & + & RFFF & - & + & - & + \\
\hline $4^{\text {a) }}$ & 32 & 30 & Female & BCC/Ear & + & Wedge resection & - & - & - & + \\
\hline $5^{\text {a) }}$ & 22 & 21 & Female & MM/Scalp & + & Rotation flap & + & - & - & + \\
\hline $6^{\mathrm{a}, \mathrm{b})}$ & 32 & 25 & Female & MM/Face & + & Facial resurfacing with STSG & + & - & - & + \\
\hline 7 & 43 & 28 & Female & MM \& SCC/Face ${ }^{c)}$ & + & Monoblock FTSG & + & + & + & - \\
\hline 8 & 39 & 38 & Male & SCC/Orbit & + & FTSG & + & - & - & - \\
\hline 9 & 10 & 8 & Male & SCC/Nose \& ear & + & Wedge resection & + & - & - & - \\
\hline $10^{b)}$ & 33 & 27 & Female & SCC/Upper lip & + & RFFF & + & + & - & - \\
\hline 11 & 37 & 36 & Female & BCC/Lower lid & + & Tenzel rotation flap & - & - & - & - \\
\hline
\end{tabular}

SCC, squamous cell carcinoma; VRAM, vertical rectus abdominis myocutaneous flap; RFFF, radial forearm free flap; BCC, basal cell carcinoma; MM, malignant melanoma; STSG, split thickness skin graft; FTSG, full thickness skin graft.

a)Patient 1 and 2, patient 3 and 4, patient 5 and 6 are siblings with each other; ${ }^{b}$ Patient 3, 6, and 10 had concomitant neurological degeneration; ${ }^{\mathrm{c} P a t i e n t} 7$ had been treated due to multifocal malignant melanoma on her whole face, and newly formed SCC was present on her lower lip. 


\section{RESULTS}

Clinical characteristics of the patients are shown in Table 1 . The mean age was 32 (range, 10-43); 4 were male and 7 were female. Six patients had SCC, 2 had malignant melanoma, 2 had BCC, and a single patient had a combination of malignant melanoma and SCC. The most common tumor location was the orbital re-

\section{Fig. 2. Patient 3 with right-sided periorbital malignancy}

Periorbital SCC with significant ulceration and destruction on the right side of the face. Tumor shows extension to periorbital soft tissues and globe. Wide resection and orbital exenteration was offered, but the patient did not consent to exenteration; thus palliative resection was performed due to persistent bleeding from the tumor bed and aesthetic problems in this patient. SCC, squamous cell carcinomas.

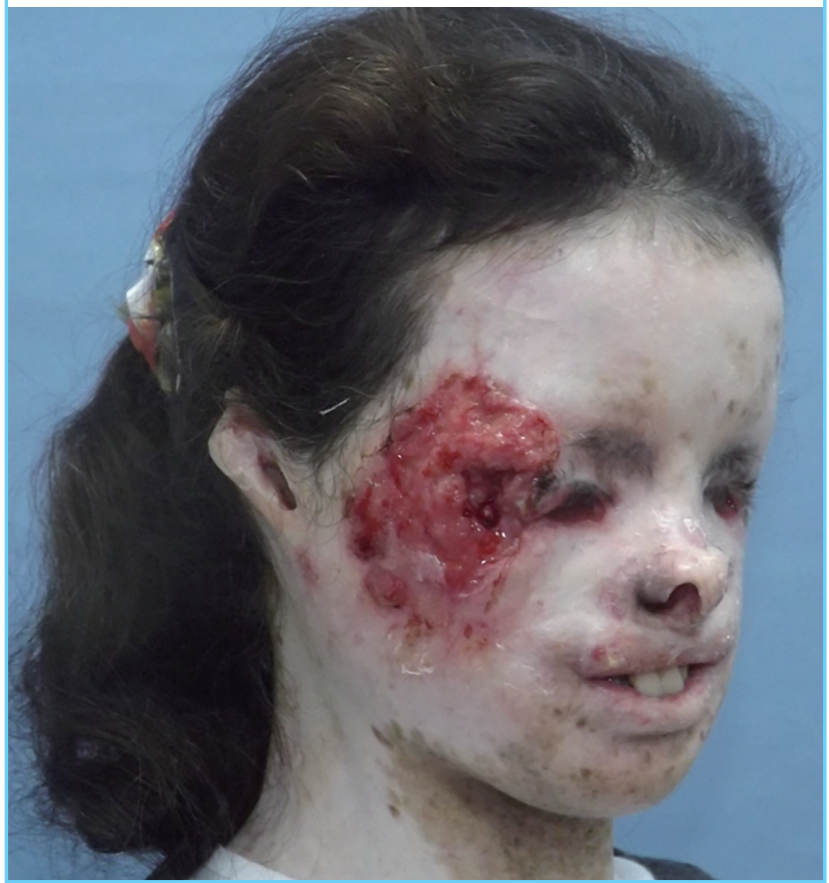

gion $(n=4)$, followed by multiple facial foci $(n=2)$, the ear $(n=1)$, the ear and nose $(n=1)$, the scalp $(n=1)$, the lower eyelid $(n=1)$, and the upper lip $(n=1)$, in decreasing frequency $(n=1)$ (Fig. 1). Following tumor excision, intraoperative frozen section analysis was performed in all patients and all except one patient (patient 3) had a negative surgical margin. Patient 3 had ocular invasion and did not consent to exenteration; palliative resection with orbital preservation and free flap reconstruction was performed to address aesthetic problems; thus that patient had a positive surgical margin (Fig. 2). The most common operation type was reconstruction with a free flap $(n=4)$ (radial forearm flap $n=2$, vertical rectus abdominis muscle [VRAM] flap $n=2$ ). In addition, wedge resection and primary repair $(n=2)$, fullthickness skin grafting $(\mathrm{n}=2)$ (Fig. 3) (one was applied monob-

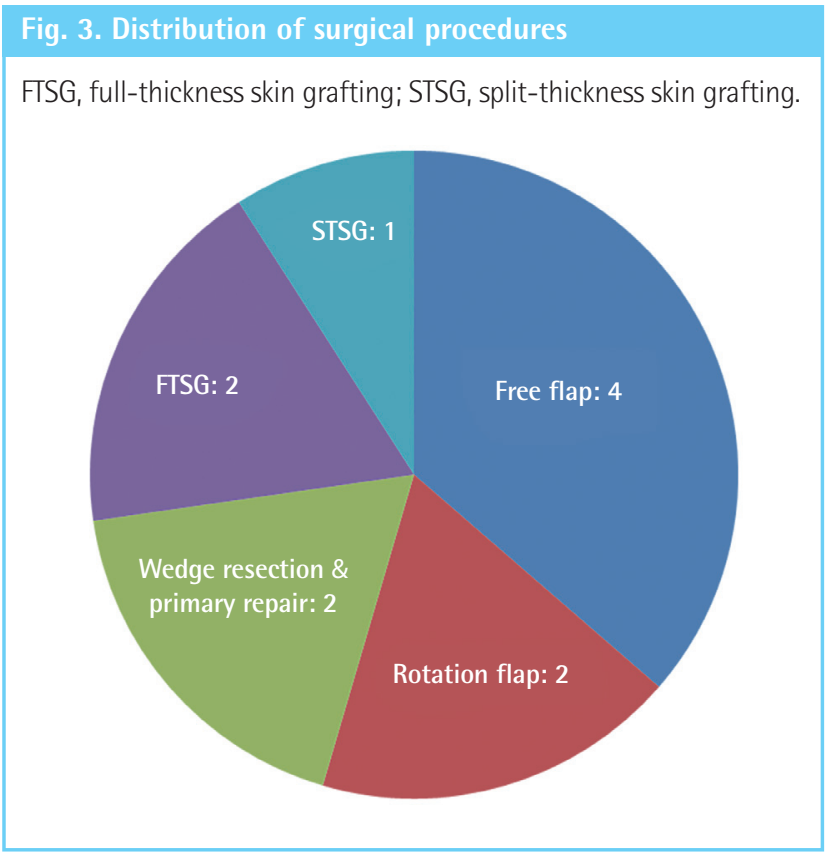

Table 2.Tumor size and surgical margins according to patient

\begin{tabular}{|c|c|c|c|c|}
\hline Patient no. & Tumor type & Tumor size $(\mathrm{cm})$ & Safety margin (mm) & No. of operations (recurrence) \\
\hline 1 & SCC & $8.0 \times 7.5$ & 14 & 25 \\
\hline 2 & SCC & $7.0 \times 6.5$ & 11 & 11 \\
\hline 3 & SCC & $7.5 \times 4.5$ & -a) & 3 \\
\hline 4 & $\mathrm{BCC}$ & $2.0 \times 1.5$ & 4 & 2 \\
\hline 5 & MM (Breslow: 5 mm) & $5.5 \times 4.3$ & 23 & 2 \\
\hline 6 & MM (Breslow: 2 mm) & Multifocal face & -b) & 3 \\
\hline 7 & MM (Breslow: 2.5 mm) & Multifocal face & -b) & 3 \\
\hline 8 & SCC & $4.7 \times 4.0$ & 12 & 2 \\
\hline 9 & SCC & $3.2 \times 2.5$ & 7 & 4 \\
\hline 10 & SCC & $8.0 \times 6.0$ & 8 & 5 \\
\hline 11 & $\mathrm{BCC}$ & $1.7 \times 1.5$ & 4 & 1 \\
\hline
\end{tabular}


Fig. 4. Siblings with xeroderma pigmentosum

Patient $3(\mathrm{~A})$ and 4 (B), patient 5 (C), and 6 (D) were siblings.
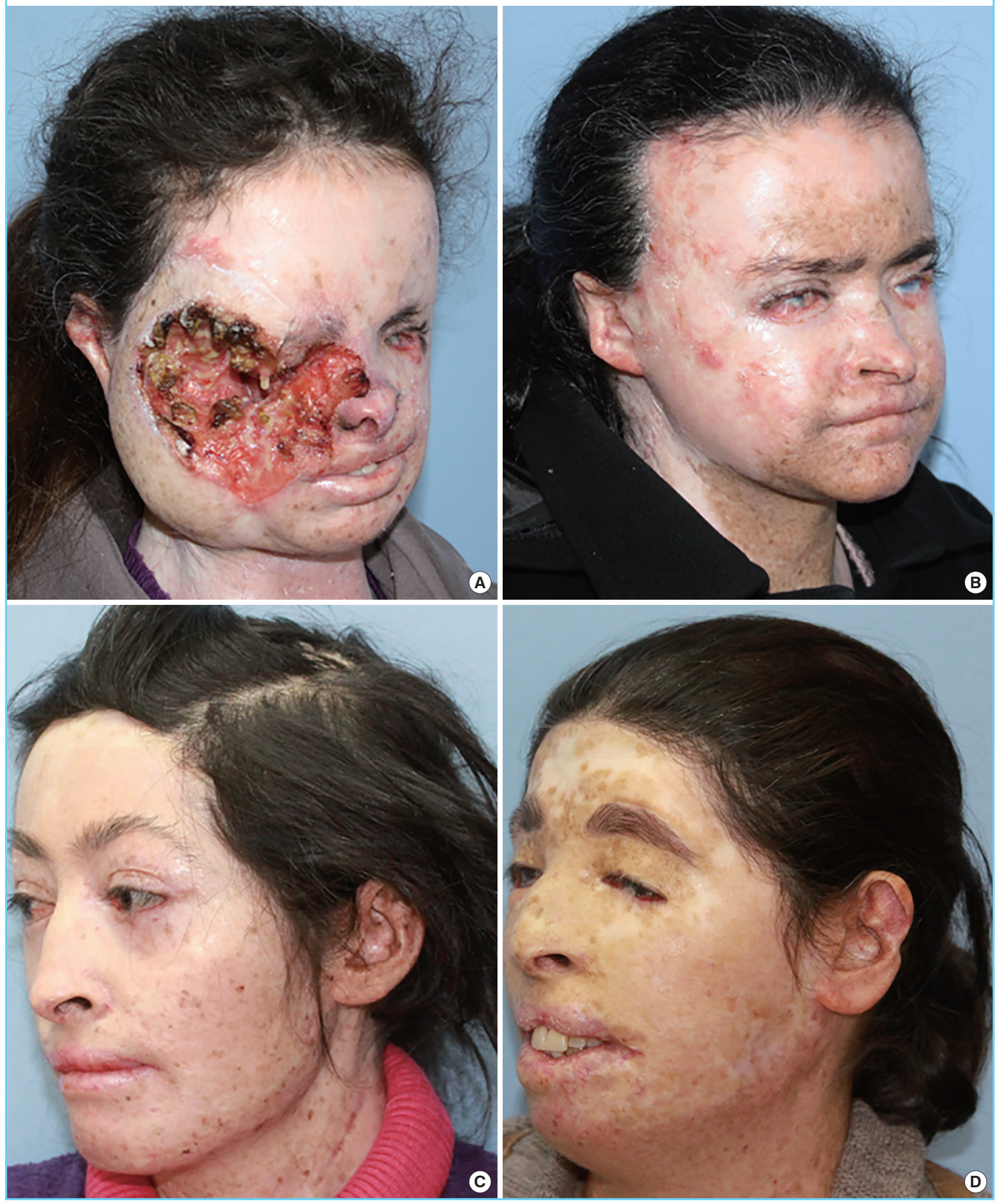
loc to the entire face, patient 7$)$, repair with rotation flap $(n=2)$, and partial-thickness skin grafting to the entire face $(n=1$, patient 6) were the other preferred procedures. The mean number of operations per patient was 5.5 (range, 1-25), and a multidisciplinary approach was used in 4 patients. The criteria for preferred spared surgical margins was $4 \mathrm{~mm}$ for BCC and a minimum of $6 \mathrm{~mm}$ for SCC. The Breslow thickness was used as a guide for the surgical margins for melanoma (Table 2). Following excision, 8 patients received adjuvant treatment (chemotherapy, radiotherapy \pm interferon) and three patients (patients 1, 2, and 7) developed lung metastasis during follow-up. Three patients $(27 \%)$ had accompanying neurological degeneration (patients 3, 6, and 10). Six patients were siblings (Fig. 4). The mean duration of follow-up was 6 years (range, 1-15 years) and 5 patients (45\%) developed recurrent lesions during follow-up. One of the patients with recurrence (patient 1 ) died due to rapid spread of tumors with resulting pneumonia and respiratory

\section{Fig. 5. Aggressive SCC on the central part of the face}

Patient 1 had undergone surgery for right orbital SCC and reconstruction with a VRAM flap previously. Despite achievement of a negative surgical margin, aggressive local recurrence occurred at 18 months after the first operation. After the second resection, the wound was left open until the final histopathological diagnosis had been reported. The patient died two months after the second operation due to pneumonia and sepsis. SCC, squamous cell carcinomas; VRAM, vertical rectus abdominis muscle.

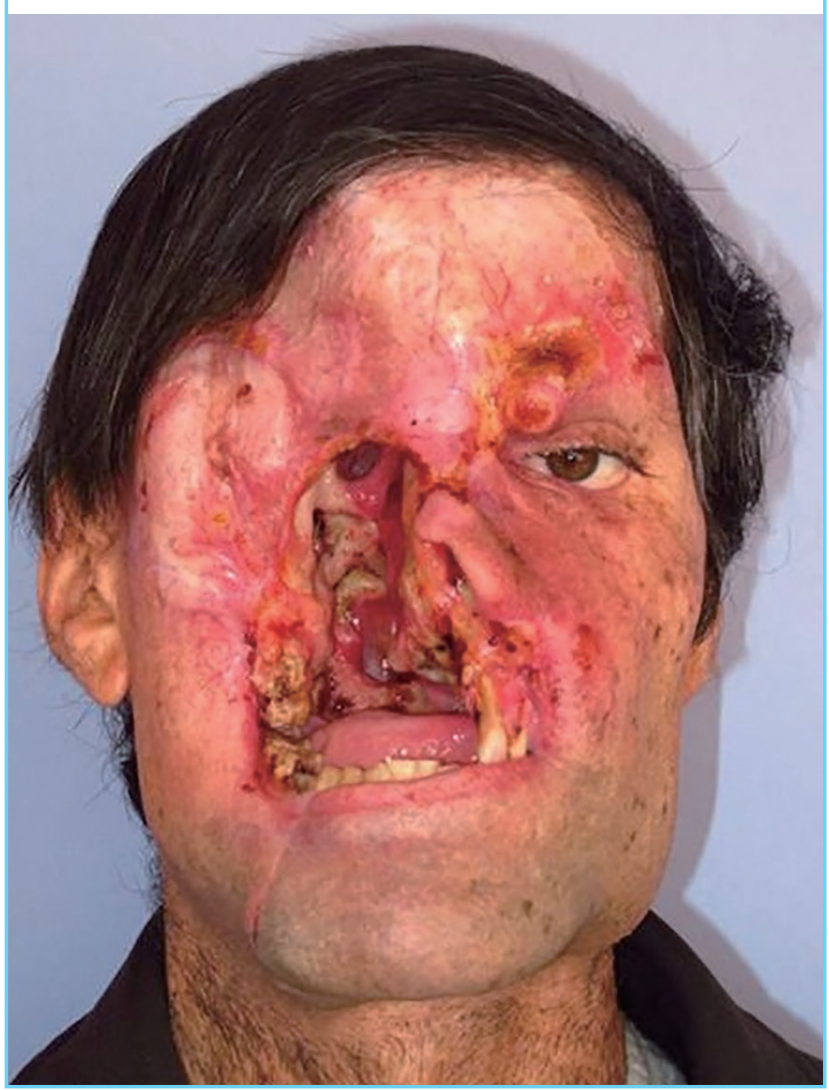

failure (Fig. 5).

\section{DISCUSSION}

In addition to its well-known skin and ocular involvement, XP may also affect the central nervous system. Previous studies have reported neurological degeneration in $25 \%-30 \%$ of these patients [9-12]; similarly, 27\% of the patients in this study had a neurological deficit (sensorineural hearing loss in patients 3 and 6 and vocal cord paralysis in patient 10). This finding is in line with previous reports, despite the limited number of patients. Classical treatment of the disease consists of sun protection and excision of cancerous and precancerous lesions. Cumulative solar injury, particularly in the head and neck region, and the natural course of the disease both play a role in the development of recurrent malignancies, which occurs in almost all patients. In this study, almost half of the patients (45\%) developed secondary malignancies within 5 years. Thus, considering the possibility of future recurrences and associated morbidities, excision should be done in an attempt not to leave residual tumor but at the same time with economical use of the tissues and without unnecessary resection [13]. The surgical team should adopt a delicate balance between tumor-free resection and maximum tissue protection. In these patients, new resections and subsequent reconstructions are complicated by previous surgery and/ or radiotherapy at the same site. We believe that wide resection should be reserved for the treatment of cavitary lesions with an aggressive course or when subsequent repair with a free-flap is planned. Wide resections for other lesions and recurrent lesions at the same site may result in substantial morbidity. Grafting after monobloc resection has also been suggested as an alternative treatment in previous studies, particularly for multiple cutaneous malignancies of the face that are close to each other [14-16]. In this study, patient number 6 and 7 had been treated with this method 18 and 10 years ago, respectively; and no recurrence was seen at the graft site during follow-up (Fig. 6). When this finding is considered, monobloc grafting offers an advantage in terms of ease of treatment and follow-up in patients with multifocal facial involvement. Mohs surgery is a widely accepted method for the treatment of such patients [2,17]; however, it is not feasible in our country due its high cost and limited number of centers capable of performing this operation $[18,19]$. Every surgical resection should be tailored individually for each patient and the benefit/harm ratio should be taken into consideration. Radiotherapy has an important role in reducing the risk of recurrence and metastatic disease. Previous studies did not show an increased risk associated with radiotherapy in these patients when compared to a normal population; thus, it can be safely 
Fig. 6. Monobloc resurfacing in xeroderma pigmentosum

Patient 7 with multiple melanomas on her face (A). Intraoperative photo after wide resection (B) and resurfacing with a monobloc full-thickness skin graft, which was harvested from the abdomen with abdominoplasty (C). The same patient at the 15th year postoperatively. The midline ulceration on her lower lip should be noted. She is scheduled for resection (D).
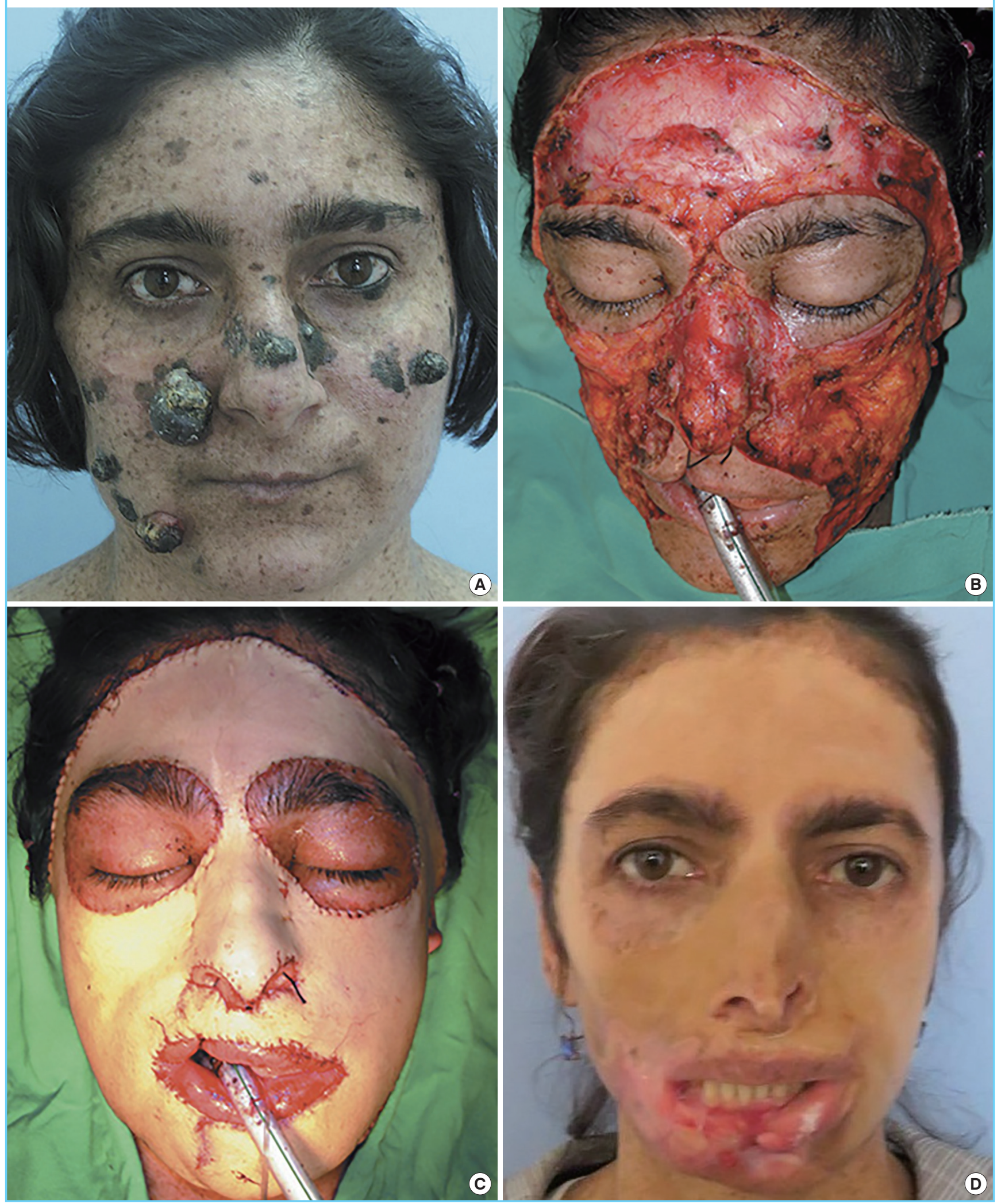
used in this patient population for the purpose of local tumor control [20-22]. In this study, only patient 3 did not undergo radiotherapy. In that patient, the tumor was in the orbital region with close proximity to the right eye, and the left eye had near complete visual loss; thus, radiotherapy was not given to avoid radiotherapy-induced vision loss in the right eye (Fig. 2). Owing to genetic penetrance of the disease, multiple affected individuals may be present in the family with diverse clinical courses. An individual with an aggressive clinical course may be an important source of stress for other siblings affected by the disease. In such situations, additional motivation and psychological support may be frequently required, and families should be informed on the variability of the clinical course across different siblings. Average survival is an important issue to be addressed. Subtype of the disease, tumor histology, and patient neglect all have effects on survival. In this study, the clinical course of XP patients with malignant melanoma was milder than the clinical course of malignant melanoma patients in the general population, which is in line with previous reports [23]. However, SCC in $\mathrm{XP}$ patients shows a more aggressive and accelerated course when compared to SCC in the normal population. Although previous studies emphasize the importance of close follow-up with a multidisciplinary approach [16], our search did not reveal any data on follow-up frequency or duration. We adopted the following protocol for our patients: every month during the first year, every 3 months for the next year, and then lifelong follow-up visits every 6 months. In conclusion, this patient population differs from the normal population in terms of surgical planning, tumor resection, adjuvant treatment, follow-up, and even social life. Thus, genetic counseling, solar protection, and a multidisciplinary approach have utmost importance [24].

\section{REFERENCES}

1. Braun-Falco O. Dermatology. Berlin: Springer; 2000.

2. Kraemer KH. Heritable diseases with increased sensitivity to cellular injury. In: Freedberg IM, Fitzpatrick TB, editors. Fitzpatrick's dermatology in general medicine. 5th ed. New York: McGraw-Hill, Health Professions Division; 1999. p.184862.

3. Gard D. Nonpigmented premalignant lesions of the skin. Clin Plast Surg 1987;14:413-23.

4. Bernerd F, Asselineau D, Frechet M, et al. Reconstruction of DNA repair-deficient xeroderma pigmentosum skin in vitro: a model to study hypersensitivity to UV light. Photochem Photobiol 2005;81:19-24.

5. Hebra F, Kaposi M. On diseases of the skin including exanthemata. New Sydenham Soc 1874;61:252-8.
6. de Laat WL, Jaspers NG, Hoeijmakers JH. Molecular mechanism of nucleotide excision repair. Genes Dev 1999;13:76885.

7. Berneburg M, Lehmann AR. Xeroderma pigmentosum and related disorders: defects in DNA repair and transcription. Adv Genet 2001;43:71-102.

8. Kilic S. Kseroderma pigmentozum. Guncel Pediatri 2004;2: $138-40$.

9. Kraemer KH, Lee MM, Scotto J. Xeroderma pigmentosum: cutaneous, ocular, and neurologic abnormalities in 830 published cases. Arch Dermatol 1987;123:241-50.

10. Robbins JH, Kraemer KH, Lutzner MA, et al. Xeroderma pigmentosum: an inherited diseases with sun sensitivity, multiple cutaneous neoplasms, and abnormal DNA repair. Ann Intern Med 1974;80:221-48.

11. Kraemer KH, Patronas NJ, Schiffmann R, et al. Xeroderma pigmentosum, trichothiodystrophy and Cockayne syndrome: a complex genotype-phenotype relationship. Neuroscience 2007;145:1388-96.

12. Rapin I, Lindenbaum Y, Dickson DW, et al. Cockayne syndrome and xeroderma pigmentosum. Neurology 2000;55: 1442-9.

13. Lasso JM, Yordanov YP, Pinilla C, et al. Invasive basal cell carcinoma in a xeroderma pigmentosum patient: facing secondary and tertiary aggressive recurrences. J Craniofac Surg 2014;25:e336-8.

14. Ozmen S, Uygur S, Eryilmaz T, et al. Facial resurfacing with a monoblock full-thickness skin graft after multiple malignant melanomas excision in xeroderma pigmentosum. J Craniofac Surg 2012;23:1542-3.

15. Atabay K, Celebi C, Cenetoglu S, et al. Facial resurfacing in xeroderma pigmentosum with monoblock full-thickness skin graft. Plast Reconstr Surg 1991;87:1121-5.

16. Ergun SS, Cek DI, Demirkesen C. Is facial resurfacing with monobloc full-thickness skin graft a remedy in xeroderma pigmentosum? Plast Reconstr Surg 2002;110:1290-3.

17. Aslan G, Karacal N, Gorgu M. New tumor formation on splitthickness skin grafted areas in xeroderma pigmentosum. Ann Plast Surg 1999;43:657-60.

18. Elcin G. How to perform Mohs micrographic surgery? Arch Turkish Dermatol Venerol 2015;49:238-45.

19. Elcin G. Mohs micrographic surgery: what if there is no Mohs micrographic surgery in Turkey? Arch Turkish Dermatol Venerol 2015;49:236-7.

20. Schaffer JV, Orlow SJ. Radiation therapy for high-risk squamous cell carcinomas in patients with xeroderma pigmentosum: report of two cases and review of the literature. Dermatology 2011;223:97-103. 
21. DiGiovanna JJ, Patronas N, Katz D, et al. Xeroderma pigmentosum: spinal cord astrocytoma with 9-year survival after radiation and isotretinoin therapy. J Cutan Med Surg 1998;2: 153-8.

22. Sancar A, Lindsey-Boltz LA, Unsal-Kacmaz K, et al. Molecular mechanisms of mammalian DNA repair and the DNA damage checkpoints. Annu Rev Biochem 2004;73:39-85.
23. Lambert WC, Lambert MW. Development of effective skin cancer treatment and prevention in xeroderma pigmentosum. Photochem Photobiol 2015;91:475-83.

24. Kocabalkan O, Ozgur F, Erk Y, et al. Malignant melanoma in xeroderma pigmentosum patients: report of five cases. Eur J Surg Oncol 1997;23:43-7. 